\title{
Syndromic surveillance in religiious festival involving circumambulation in India
}

\author{
Vishal Diwan ${ }^{\star 1,3}$, Ponnaiah Manickam², Viduthalai virumbi Balagurusamy ${ }^{2}$, \\ Priyank Soni ${ }^{1}$, Ashish Pathak ${ }^{1,3}$, Jeromie wesley Thangaraj ${ }^{2}$, Vivek Parashar ${ }^{1}$, \\ P Ganeshkumar², Chandrasekar Ravichandran², Ankit Garg', Madhusudhana Rao², \\ Sendhil Kumar², V Vettrichelvan², Manoj Murhekar² and Vijay K. Mahadik
}

${ }^{1}$ Public Health and Environment, R.D. Gardi Medical College, Ujjain, India; ${ }^{2}$ National Institute of Epidemiology, Chennai, India; ${ }^{3}$ Karolinska Institutet, Stockholm, Sweden

\section{Objective}

To study operation feasibility and prepadness of a a tablet-based participatory syndromic surveillance among pilgrims during annual ritual circumbulation (Panchkroshi Yatra) coveirng 15 miles daily in Ujjain, Madhya Pradesh India

\section{Introduction}

Panchkroshi yatra is an annual ritual of circumambulation (yatra) of temples (Mahadevs) and 100,000 devotees walk for around 15 miles per day for six days and cover a total of 73 miles to worship important Mahadevs. The festival is held every year at the city of Ujjain, Madhya Pradesh, Central India. The yatra attracts large number of pilgrims especially from rural areas and usually women outnumber men. During the yatra, the pilgrims halt at several places and prepare their food in outdoors. We described the public health preparedness, implemented a tablet-based participatory syndromic surveillance among pilgrims of the yatra and reviewed satisfaction of the pilgrims regarding implementation of public health measures, Ujjain during 21-26, April, 2017.

\section{Methods}

We described preparedness and arrangements done for the Yatra. We designed tablet-based android to collect information from pilgrims on socio-demographic-economic details, location and self-reported health problems (syndromes). Trained investigators collected data from consenting pilgrims at strategically located halting places. We interviewed a convenient sample of consenting participants to assess satisfaction regarding the public health measures such as sanitation, water, safety, food and cleanliness.

\section{Results}

The district team organized round-the-clock medical camps in strategic locations (mainly at temple or halting place) of the route of the Yatra with few camps having admission facility for emergency conditions. There were no mobile medical units. Ambulance services were on standby at all medical camps. Our satisfactory survey of 360 participants indicated that $79 \%$ were satisfied with these medical facilities (79\%). District administration alongwith local village administration (panchayat) had set up outlets selling provisions necessary meeting cooking needs. Eighty percent pilgrims were satisfied with food and refreshment arrangements. Permanent and temporary toilets were set-up at the halt-locations but not on the route. Snitation measures such as chlorination and solid waste management were in place. Pilgrims' satisfaction for urinals (53\%) and toilets $(60 \%)$ was less as compared to cleanliness (74\%). Electrical supply and lighting were arranged properly. Volunteers were available to provide assistance to pilgrims. Provision of safe drinking water and potable water were arranged by the authorities and the villageresidents made water available through well, pots etc. The survey suggested that only $5 \%$ of them were not satisfied with water related arrangements. Security arrangements such as deployment of police, crowd management, and traffic control and fire safety were wellarranged by the authorities and majority of the respondents expressed satisfaction on these arrangements (79-84\%).

We interviewed 6435 pilgrims for any self-reported symptoms. More than half $(56 \%)$ of the responders were female and majority (64\%) aged 15- 59 years. Around 44\% were from Ujjain district. Every second person (around 47\%) reported illness with one or other symptoms. Most of them complained of injury with blister (11\%). Other common complaints include stomach ache $(8 \%)$, redness in eyes $(7 \%)$, fever $(7 \%)$, cough $(6 \%)$, vomiting $(4 \%)$, diarrhea $(4 \%)$ and throat pain $(3 \%)$ (Figure)

\section{Conclusions}

The participants' response indicates that all the public health and safety measures were satisfactory except the need for setting up urinals along the fixed route of circumambulation. Table-based surveillance during the yatra indicated that injury was the most commonly selfreported health problem. Implementation of such surveillance helps in tracking health events and therefore, may facilitate preparedness and response. We recommend implementation of such tablet-based surveillance during such mass gathering events.
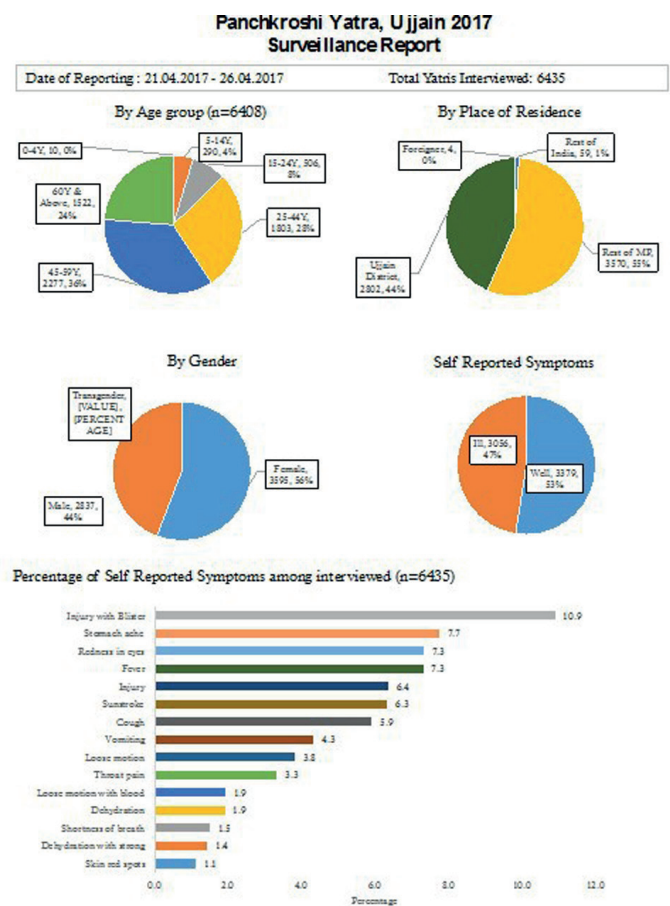

\section{Keywords}

Participatory; Mass gathering; syndromic surveillance; India 


\section{ISDS 2018 Conference Abstracts}

\section{Acknowledgments}

We are grateful for the Department of Health and Family Welfare, Government of Madhya

Pradesh for study permission, National Institute of Epidemiology, Chennai and R.D. Gardi Medical College, Ujjain for financial Support. We are also thankul to Vesper Infotech Pvt Ltd, study participants and project team

\section{References}

1. Qanta A Ahmed, Yaseen M Arabi, Ziad A Memish, Health risks at the Hajj, Lancet 2006; 367: 1008-15 2. Tam JS, Barbeschi M, Shapovalova N, Briand S, Memish ZA \& Kieny MP. Research agenda for mass gatherings: a call to action. The Lancet infectious diseases, 2012;12,3, 231-239 3. Henning KJ, Overview of syndromic surveillance. What is syndromic surveillance? MMWR Morb Mortal Wkly Rep 53 (Suppl): 5-11 (2004). 4. Chandrasekhar, CP, Ghosh $\mathrm{J}$ Information and communication technologies and health in low income countries: the potential and the constraints. Bulletin of the World Health Organization, 2001, 79: 850-855

\section{*Vishal Diwan}

E-mail: vishaldiwan@hotmail.com 